\title{
Characteristics of intermittent turbulence in the upper stable boundary layer over Greenland
}

\author{
Clemens Drüe • Günther Heinemann
}

Received: 30 May 2006 / Accepted: 25 February 2007 / Published online: 24 April 2007

(C) Springer Science+Business Media B.V. 2007

\begin{abstract}
The experiment IGLOS (Investigation of the Greenland Boundary Layer Over Summit) was conducted in June and July 2002 in the central plateau of the Greenland inland ice. The German research aircraft POLAR 2, equipped with the turbulence measurement system METEOPOD, was used to investigate turbulence and radiation flux profiles near research station "Summit Camp". Aircraft measurements are combined with measurements of radiation fluxes and turbulent quantities made from a $50 \mathrm{~m}$ tower at Summit Camp operated by Eidgenössische Technische Hochschule (ETH) Zürich. During all six flight missions, welldeveloped stable boundary layers were found. Even in high-wind conditions, the surface inversion thickness did not exceed roughly $100 \mathrm{~m}$. The turbulent height of the stable boundary layer (SBL) was found to be much smaller than the surface inversion thickness. Above the surface layer, significant turbulent fluxes occurred only intermittently in intervals on the order of a few kilometres. Turbulent event fraction in the upper SBL shows the same dependence on gradient Richardson number as reported for near-surface measurements. Clear-air longwave radiation divergence was always found to contribute significantly to the SBL heat budget. In low-wind cases, radiative cooling even turned out to be dominant.
\end{abstract}

Keywords Aircraft-based study · Greenland summit · Intermittent turbulence · Stable boundary layer

\footnotetext{
C. Drüe $(\square)$

Institut für Meteorologie und Klimatologie, Universität Hannover, Herrenhäuser Str. 2, 30419 Hannover, Germany

e-mail:druee@muk.uni-hannover.de

G. Heinemann

Umweltmeteorologie, Fachbereich Geographie/Geowissenschaften, Universität Trier, 54286 Trier, Germany

e-mail: heinemann@uni-trier.de
} 


\section{Introduction}

The exchange of energy and momentum between the atmosphere and polar ice sheets is a key factor in the climate system. The formulation of satisfactory parameterizations for transport processes in the stable boundary layer (SBL) still represents a great challenge. Inadequate parameterizations cause many current numerical weather and climate models to show great difficulties e.g. in representing the mass and energy balance of polar ice sheets. For a better understanding of the SBL, it is essential to study relevant processes at the atmosphere-snow interface (see e.g. Xiao et al. 2000; Colbeck 1997), inside the SBL and in the free atmosphere above the SBL.

Turbulence studies in the SBL are quite complicated, since intermittency of turbulence, clear-air radiation flux divergence, shear generation by a low-level jet (LLJ), density currents, gravity waves, meandering motions and surface heterogeneity have to be considered (Mahrt et al. 1998).

Intermittent turbulence, i.e. long periods of little to no turbulent activity interrupted by brief periods with significantly increased levels of activity (Mahrt 1999; Van de Wiel et al. 2002), is well known to occur under strongly stabile stratification of the planetary boundary layer (PBL; e.g. Mahrt 1998) but has also been observed under moderate and even weak stability (Doran 2004). Intermittency is particularly difficult to describe in the framework of classic similarity theory. Nieuwstadt (1984) explicitly excluded intermittent turbulence from his analysis of local scaling. Recent studies that tried to characterize intermittency were confined to mid latitudes (Doran 2004; Coulter and Doran 2002).

Past studies of the SBL over Greenland and Antarctica concentrated on the lowest part of the PBL (e.g. Handorf 1996; Handorf et al. 1999). Frequently in these studies, the measured stability parameter $\zeta=z / L$ (where $z$ is height above ground and $L$ is the Obukhov length; e.g. see Stull 1988) did not exceed a value of 2 (e.g. King 1990; Handorf et al. 1999). Other studies were conducted in the sloping regions of the ice sheets, where katabatic winds create continuous forcing of the SBL (e.g. Oerlemans and Vugts 1993; Forrer and Rotach 1997; Heinemann 2002). Hence, only moderate positive Richardson numbers and a fully turbulent SBL were found in these studies. In order to sample intermittency, Cassano et al. (2001) recommended the conduction of similar experiments on the inner Antarctic plateau. The same conditions, however, exist on the Greenland inland ice, where this study was conducted.

The field experiment described in the present publication (see Sect. 2) was intended to feed this demand for further studies of the SBL as well as of the overlying lower portion of the free atmosphere over snow surfaces. It was conducted in undisturbed conditions over a flat, homogeneous area of the Greenland inland ice. Taking turbulence measurements by aircraft allowed for the investigation of the upper part of the SBL.

We present results from this experiment in the following way: Sect. 2 gives an outline of the experimental set-up. In Sect. 3 PBL structures over the Greenland summit are summarized, including SBL height, scales of transport, and the SBL heat budget. In Sect. 4 the role of intermittent turbulence is discussed by means of turbulent event fraction and turbulent event transports. A summary and conclusions are given in the last section, Sect. 5.

\section{Data}

\subsection{The IGLOS experiment}

The experiment IGLOS (Investigation of the Greenland Boundary Layer Over Summit) was conducted from 29 June to 25 July 2002 over the Greenland Summit area. 


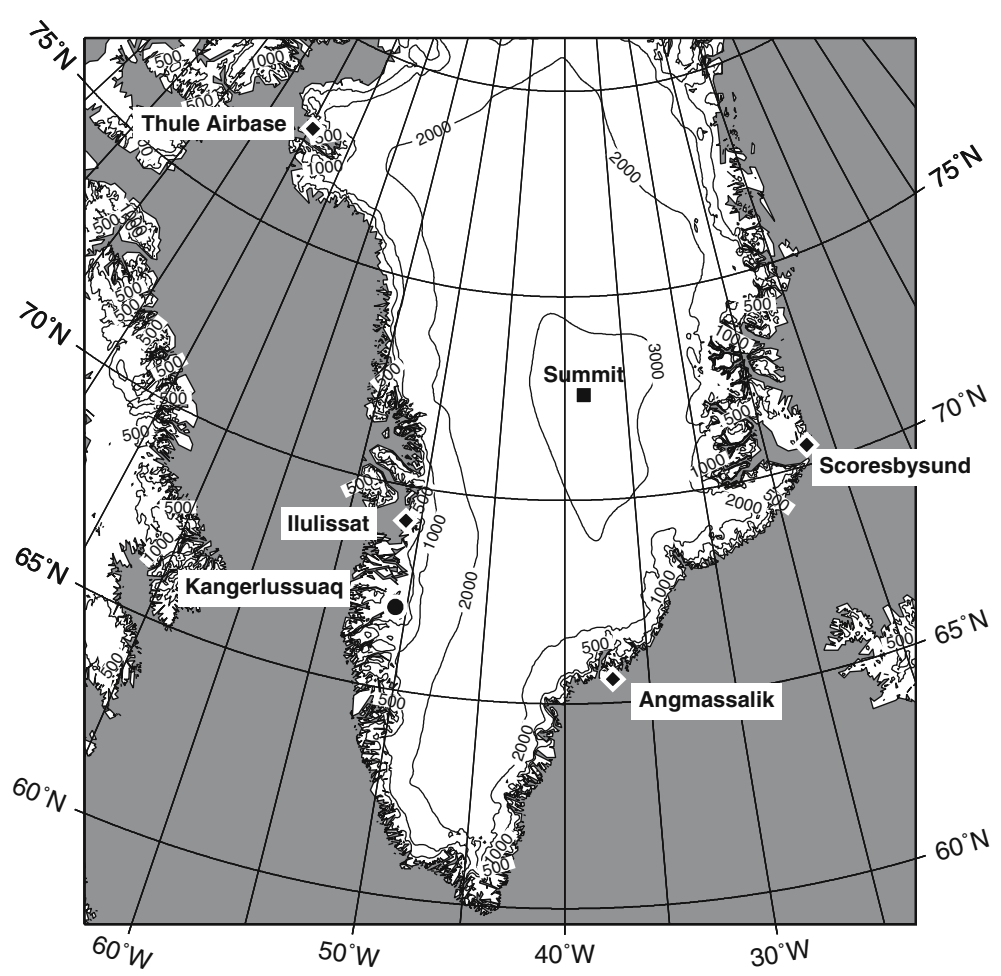

Fig. 1 Area map of Greenland. Summit Camp is marked by a square, major cities are marked by diamonds. Note elevation contours

This region was chosen, because a very flat and horizontally homogeneous terrain was needed for this investigation. In general, this applies only for two land environments: a few deserts and the inner parts of the polar ice sheets (Ohmura et al. 1998). Of such areas, only the Greenland Summit area offers well-developed SBLs and is accessible from Europe with moderate logistic effort (Fig. 1).

An in-depth description of the experiment is given in Drüe and Heinemann (2003). A summary is given in the following for the reader's convenience.

\subsubsection{Aircraft measurements}

Aircraft instrumentation: The German research aircraft "Polar2" served as the main instrument platform (Fig. 2). It is a Dornier Do228 of $17 \mathrm{~m}$ wingspan owned by Alfred-WegenerInstitut (AWI), Bremerhaven. The instrumentation of the aircraft is summarized in Table 1. Polar2 was equipped with the autonomous turbulence probe "Meteopod" (Fig. 2, Table 2). It consists of a cargo pod under the right wing with a forward boom carrying the sensors (Vörsmann 1990; Drüe and Heinemann 2001). During Meteopod operations, Polar2 typically flies at an airspeed of $65 \mathrm{~m} \mathrm{~s}^{-1}(\approx 130 \mathrm{kts})$. Aircraft motions as well as deformations of the wing are detected by an internal reference platform of the Meteopod. The fast temperature (open wire) and humidity (Ly- $\alpha$ ) sensors have time constants of less than $1.5 \times 10^{-2} \mathrm{~s}$, which corresponds very well to the $100 \mathrm{~Hz}$ sampling rate. Foken and Wichura (1996) recommended 


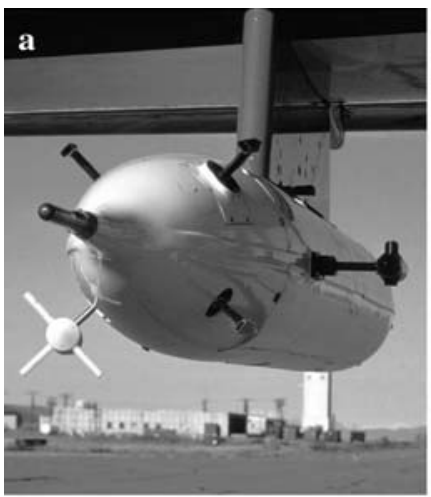

Meteopod

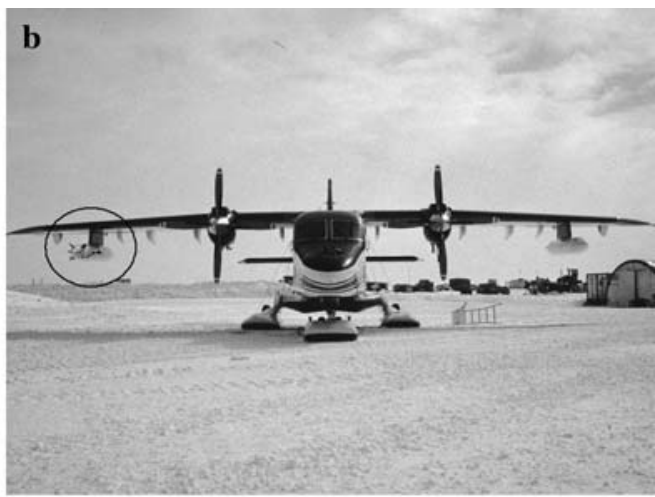

Polar2

Fig. 2 "Meteopod" turbulence measurement system and research aircraft "Polar2", parked at Summit Camp. Meteopod sensors are: five-hole probe (pointing to the left) and (following clockwise) Humicap, dew point mirror, Lyman- $\alpha$-hygrometer, Pt-100 open wire, reverse-flow thermometer (see Table 2). Note the Meteopod under the starboard wing (circle) of Polar2

Table 1 Polar 2 aircraft instrumentation (from Drüe and Heinemann 2003)

\begin{tabular}{lll}
\hline Quantity & Sampling & Sensor, manufacturer \\
\hline Position & $1 \mathrm{~Hz}$ & GPS, Garmin \\
Position/orientation & $45 \mathrm{~Hz}$ & INS, Honeywell Lasernav \\
Height & $20 \mathrm{~Hz}$ & Radar altimeter \\
& $2000 \mathrm{~Hz}$ & Laser altimeter, Ibeo \\
Pressure/airspeed & $20 \mathrm{~Hz}$ & Pitot tube, Rosemount \\
Surface temperature & $20 \mathrm{~Hz}$ & KT-4, Heimann \\
Radiation fluxes & $20 \mathrm{~Hz}$ & 2 Pyranometer, Eppley PSP \\
& & 2 Pyrgeometer, Eppley PIR \\
Temperature & $20 \mathrm{~Hz}$ & Pt100, Rosemount \\
Humidity & $20 \mathrm{~Hz}$ & Humicap+Pt100, Aerodata \\
\hline
\end{tabular}

Table 2 Meteopod turbulence measurement system instrumentation (after Drüe and Heinemann 2003)

\begin{tabular}{lll}
\hline Quantity & Sampling & Sensor, manufacturer \\
\hline Orientation & $60 \mathrm{~Hz}$ & INS, Litton LTR81 \\
Height & $100 \mathrm{~Hz}$ & Radar altimeter, Thales Research and Technology (TRT) \\
3D airspeed & $100 \mathrm{~Hz}$ & 5-hole probe, Rosemount \\
Temperature & $100 \mathrm{~Hz}$ & Pt100 open wire, Rosemount/AWI \\
& $100 \mathrm{~Hz}$ & Reverse Flow open wire, AWI \\
Humidity & $100 \mathrm{~Hz}$ & Lyman- $\alpha$, Atmospheric Instrumentation Research (AIR) \\
& $100 \mathrm{~Hz}$ & Humicap/Pt100, Vaisala/Aerodata \\
& $100 \mathrm{~Hz}$ & Dew point mirror, General Eastern (GE) \\
\hline
\end{tabular}


Table 3 Overview of the flight missions

\begin{tabular}{|c|c|c|c|c|c|c|}
\hline \multirow[t]{3}{*}{ Flight } & \multirow{3}{*}{$\begin{array}{l}\text { Date (yyyy/mm/dd), time } \\
\text { UTC }\end{array}$} & \multicolumn{4}{|c|}{ Characteristics } & \multirow{3}{*}{$\begin{array}{l}\text { Upper air } \\
\text { flow } \\
\mathrm{ms}^{-1} \text { (dir) }\end{array}$} \\
\hline & & \multicolumn{2}{|c|}{ Inversion } & \multicolumn{2}{|c|}{ Low level wind } & \\
\hline & & $\begin{array}{l}\text { Height } \\
\text { m }\end{array}$ & $\begin{array}{l}\Delta T_{0} \\
\mathrm{~K}\end{array}$ & $\begin{array}{l}\text { Height } \\
\text { m }\end{array}$ & $\begin{array}{l}\text { Max. } \\
\mathrm{ms}^{-1}\end{array}$ & \\
\hline SBL1 & 2002/07/04, 0350-0630 & 100 & - & 45,80 & 9,12 & $12(200)$ \\
\hline SBL2 & 2002/07/09, 0345-0700 & 200 & 20 & 45 & 5 & $5(290)$ \\
\hline SBL3 & 2002/07/10, 0315-0555 & 180 & 11 & 45 & 9 & $7(220)$ \\
\hline SBL4 & 2002/07/10, 0715-1005 & 240 & 11 & 200 & 9 & $7(220)$ \\
\hline SBL5 & 2002/07/11, 0010-0230 & 150 & 17 & $(35)$ & $(4.5)$ & $2.5(260)$ \\
\hline \multirow[t]{2}{*}{ SBL6 } & $2002 / 07 / 11 / 2355-$ & & & & & \\
\hline & 2002/07/12 0310 & 120 & 10 & 85 & 13 & $13(140)$ \\
\hline
\end{tabular}

$\Delta T_{0}$ denotes the difference between the inversion temperature maximum and the radiometric surface temperature (not available for SBL1). Upper air flow is determined from high aircraft temps. Height values are estimations made during the flight missions. All data represent aircraft measurements, except low-level wind data from SBL5 (Swiss Tower measurements, because low-level wind maximum was below lowest flight level). Note that time is given in UTC (Universal Time Coordinated) rather than local time

this choice because aliasing by A/D conversion compensates sensor attenuation, at least if the inertial subrange extends to either side of the sampling frequency/wavenumber.

Flight missions: The general flight strategy (Fig. 3) consisted of two elements: constantlevel runs of $30 \mathrm{~km}$ length were flown at different heights, upstream of the ground instrumentation, to yield turbulent fluxes. A saw-tooth pattern ("aircraft temps") was flown forming a $30 \mathrm{~km}$ by $30 \mathrm{~km}$ box around the central leg to yield the horizontal and vertical structure of the PBL in the shortest possible time. Aircraft temps extend typically from $30 \mathrm{~m}$ to $400 \mathrm{~m}$. The height of the horizontal runs was chosen depending on a vertical temperature profile (typically $900 \mathrm{~m}$ height) that was measured right after each takeoff. A typical set of heights of the horizontal runs is: $30 \mathrm{~m}, 60 \mathrm{~m}, 90 \mathrm{~m}$, and $130 \mathrm{~m}$.

During IGLOS, a total of six such flight missions could be performed (referenced as cases SBL1 to SBL6 in the following), that cover a wide range of different synoptic framework conditions (Drüe and Heinemann 2003). To encounter a well-developed SBL during Arctic summertime, all flight missions were carried out during clear nights, when high-pressure conditions were present over central Greenland. Takeoff time was chosen close to the occurrence of the daily temperature minimum (Table 3).

Data processing: Instrument calibration and in-field data processing were performed by Optimare AG (Bremerhaven), and re-processing of the data was done at the Meteorologisches Institut der Universität Bonn (MIUB) for a number of meteorological quantities (Drüe and Heinemann 2001).

The raw data processing is identical to Heinemann (2002): the calculation of the horizontal wind is based on a frequency-separating merging of the fast (but drifting) inertial navigation system (INS) with the global positioning system (GPS) measurements. Humidity was calculated by correcting the drift and offset of the Ly- $\alpha$ sensor using the dew point mirror measurements. Temperature measurements of slow and fast sensors (Table 2) are combined by frequency-separating merging (see Vörsmann 1990; Drüe and Heinemann 2001). Data from horizontal flight sections were then interpolated to a $0.5 \mathrm{~m}$ grid. Data from aircraft temps 
were averaged over vertical $25 \mathrm{~m}$ bins to yield vertical profiles (see Drüe and Heinemann 2001).

As explained in Heinemann (2002), a straightforward computation of mean quantities and fluctuations (as deviation of the means) for the determination of turbulence statistics would not be successful. Data from horizontal flight sections have to be filtered for separating the turbulence signal from other variations, such as variations of the aircraft height. Heinemann (2002) used high-pass filtering for this purpose. Instead, we chose to calculate turbulent fluxes for each $500 \mathrm{~m}$ section of every constant level run, using linear detrending. Different conditioning methods were tested, as recommended by Moncrieff et al. (2004). But the results were found to differ by much less than the calculated random errors. Linear detrending behaves in the frequency domain more similar to the high pass filtering of Heinemann (2002) than to block averaging (Finnigan et al. 2003). $500 \mathrm{~m}$ averaging length was used because during IGLOS, turbulent motions are found only on length scales below roughly $500 \mathrm{~m}$, as will be demonstrated by a spectral analysis in Sect. 3.2. The flux values calculated for all $500 \mathrm{~m}$ intervals are then averaged over each run. Note that the error of the averaged fluxes decreases with the square root of the number of $500 \mathrm{~m}$ intervals. The uncertainty of the averaged fluxes is hence identical to sampling over the full length of the horizontal run (see e.g. Kaimal and Finnigan 1994).

\subsubsection{Ground instrumentation}

In order to provide ground truth and to extend vertical profiles down to the ground, aircraftbased measurements were combined with ground-based measurements. For this purpose, continuous turbulence measurements were taken by a METEK USA-1 ultrasonic 3D anemometer on a $3 \mathrm{~m}$ mast in the centre of the flight area (Fig. 3). The position of this mast called "S9" was $10 \mathrm{~km}$ south of the research station Summit Camp.

At Summit Camp, Eidgenössische Technische Hochschule (ETH) Zürich operated a $50 \mathrm{~m}$ profiling mast ("Swiss Tower") from July 2001 to August 2002 (Schelander et al. 2004). It was equipped with cup anemometers, temperature, and humidity sensors at eight levels between $0.5 \mathrm{~m}$ and $50 \mathrm{~m}$ above ground. For more details see Drüe and Heinemann (2003). Furthermore, radiation balance was measured by upward and downward looking pyranometers and pyrgeometers at four levels on the mast.

\section{Boundary-layer structures}

\subsection{SBL height}

In all SBL cases, well-developed stable boundary layers were found. The vertical extent of the surface inversion was mostly below the values suggested by previous studies (e.g. Handorf et al. 1999; Heinemann 1998). Even in high-wind conditions (more than $10 \mathrm{~m} \mathrm{~s}^{-1}$ ), the surface inversion thickness did not exceed roughly $100 \mathrm{~m}$.

Figure 4 shows two examples of vertical temperature profiles, one from a low-wind (SBL2) and one from a high-wind (SBL6) case. We plotted air temperature since potential temperature takes confusingly high values due to the high elevation of the experimental area. Above the surface inversion, winds of $5 \mathrm{~m} \mathrm{~s}^{-1}$ from $220^{\circ}$ were measured during SBL2 and $12 \mathrm{~m} \mathrm{~s}^{-1}$ from $140^{\circ}$ during SBL6. Above the surface inversion, the stratification of the atmosphere remains slightly stable because of a synoptic high pressure system over the investigation area. Thermal SBL height shown in both profiles was determined as suggested by Heinemann (1999). 


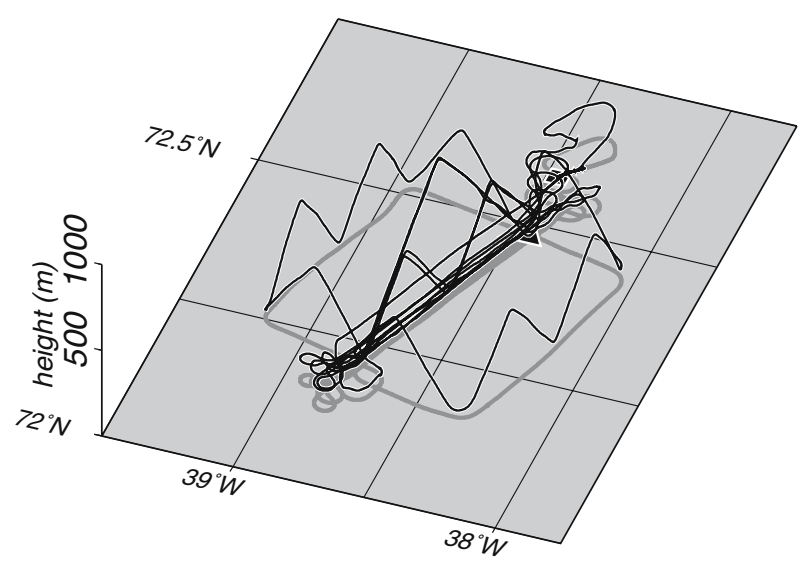

Fig. 3 Typical flight strategy (Flight SBL4 on July 10, 2002). The triangle marks the position of station S9 (see text) used as anchor point when rotating the pattern according to the low-level flow

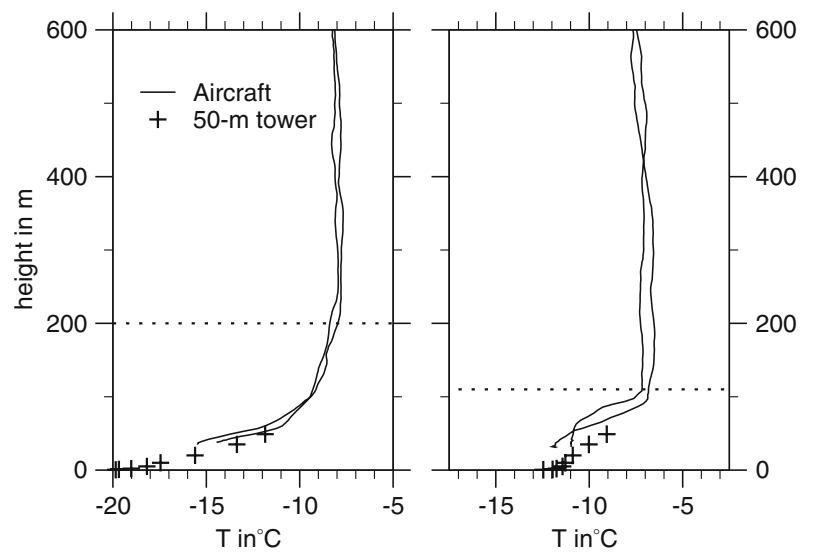

Fig. 4 Vertical profiles of air temperature measured by aircraft (lines; two consecutive profiles) and ETH $50 \mathrm{~m}$ tower (crosses). Left panel shows a low-wind case (SBL2; 0420 UTC), right panel shows a high-wind case (SBL6; 0025 UTC). Dotted horizontal lines mark the thermal SBL heights $h_{T}$ (see text for definition)

In that study, the level where $\partial \theta / \partial z=0.015 \mathrm{~K} \mathrm{~m}^{-1}$ (or $\partial T / \partial z=0.005 \mathrm{~K} \mathrm{~m}^{-1}$ ) was found to be a good estimate for the thermal SBL height $h_{T}$. Here $T$ denotes temperature, $\theta$ potential temperature and $z$ height above ground.

At the lowest flight level of $30 \mathrm{~m}$-which is below a low-level wind maximum in all cases (Fig. 5)-turbulence intensity was found to be weak in general, although vertical wind shear ranges up to $0.15 \mathrm{~s}^{-1}$ at this level. While the decrease of turbulent kinetic energy (TKE) with height appears fairly linear among the flight levels (Fig. 6), TKE at the lowest flight level is only $50 \%$ of its surface value. Turbulent momentum fluxes (not shown) even drop to less than $10 \%$ at this level. For both SBL2 and SBL6, this drop is even stronger than observed by Heinemann (2002) in the katabatic SBL over Greenland.

Above the low-level wind maximum, turbulence intensity almost vanishes in all cases (not shown) although a significant vertical wind shear was found above the low-level wind maximum (Fig. 5) in many cases. Hence, the height of the low-level wind maximum $h_{v}$ proved to 


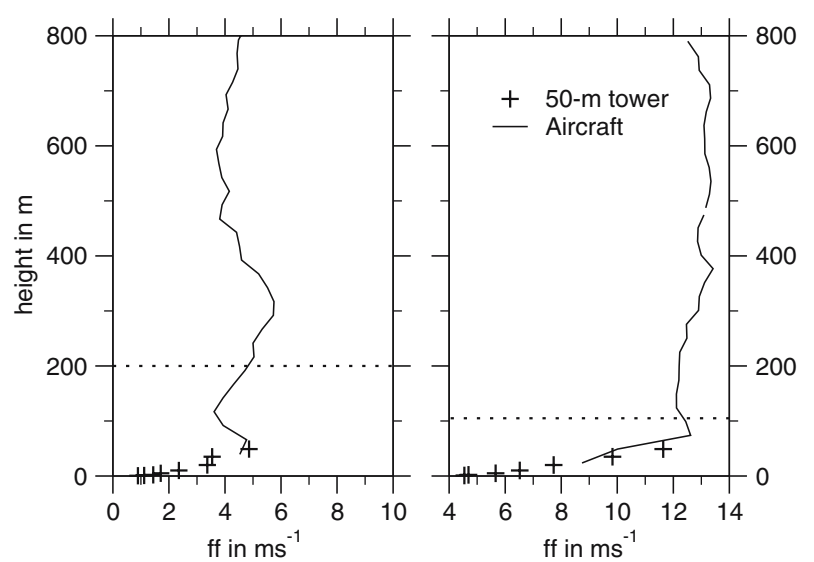

Fig. 5 Vertical profiles of wind speed, same representation as Fig. 4
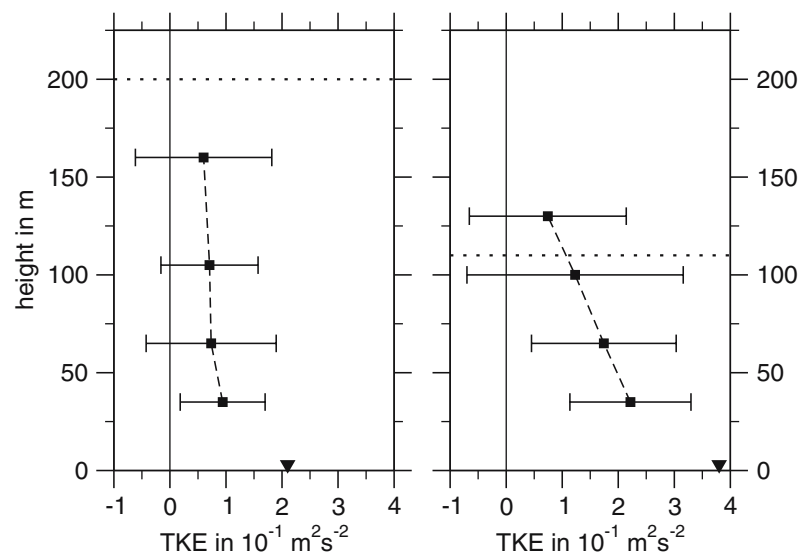

Fig. 6 Vertical profiles turbulent kinetic energy (TKE). Left panel shows SBL2, right panel shows SBL6. The used averaging length is $500 \mathrm{~m}$, squares represent averages over $30 \mathrm{~km}$ constant-level runs. Error bars give the standard deviation of the averaged values. Triangles denote surface values from station S9. Dots indicate the inversion height, as in Fig. 4

be a good estimate for the turbulent SBL height in our cases. In contrast to previous studies (e.g. Handorf et al. 1999; Heinemann 1999), this turbulent height of the SBL was found to be smaller than the surface inversion thickness $h_{T}$ in all cases during IGLOS.

In the past, a considerable number of SBL height estimates has been published (Nieuwstadt 1984; Mahrt 1981; and others). Most of them relate SBL height to the friction velocity $u_{*}$. One of the most recent approaches of this kind is the 'corrected quasi equilibrium (CQE) SBL height' $\left(h_{C Q E}\right)$ presented by Zilintinkevich and Baklanov(2002),

$$
\begin{aligned}
\frac{1}{h_{C Q E}} & =\frac{1}{h_{Q E}}+\frac{1}{h_{*}}, \\
h_{Q E} & =\frac{C_{R} u_{*}}{|f|}\left[1+\frac{C_{R}^{2} u_{*}\left(1+C_{u N} N L / u_{*}\right)}{C_{S}^{2}|f| L}\right]^{-1 / 2}+\frac{w_{h}}{C_{E}|f|},
\end{aligned}
$$


Table 4 Averages of thermal $h_{T}$, turbulent $h_{v}$ SBL height and $h_{C Q E}$ after Zilintinkevich and Baklanov (2002)

\begin{tabular}{llll}
\hline Case & $h_{T}$ in $\mathrm{m}$ & $h_{v}$ in $\mathrm{m}$ & $h_{C Q E}$ in m \\
\hline SBL2 & 200 & 45 & 65 \\
SBL3 & 180 & 45 & 38 \\
SBL4 & 240 & 200 & 150 \\
SBL5 & 150 & $(35)$ & 45 \\
SBL6 & 120 & 85 & 140 \\
\hline
\end{tabular}

Values for SBL1 could not be calculated due to a partial data loss. Values in brackets are based on Swiss Tower data

with $C_{R}=0.4, C_{u N}=0.25, C_{S}=0.75, C_{E}=1$ and $h_{*}=3000 \mathrm{~m}$ being empirical constants, $w_{h}$ the large-scale vertical velocity (here calculated from horizontal wind divergence around the flight pattern), $L$ the Obukhov length, $f$ the Coriolis parameter and $N$ the Brunt-Väisälä frequency of the free atmosphere.

Especially in moderate to low-wind cases, our data show that $h_{C Q E}$ matches better with the measured turbulent SBL height $h_{v}$ than with the thermal SBL height $h_{T}$. In high-wind cases, $h_{v}$ approaches $h_{T}$ and hence $h_{C Q E}$ matches both of them in a similar way. Mean values of $h_{T}, h_{v}$, and $h_{C Q E}$ for each case (averaged over all available aircraft temps) are given in Table 4.

Although $h_{C Q E}$ includes stability above the SBL, it is calculated mainly from turbulent properties of the surface layer. Apparently, the thickness of the surface inversion deviates from this estimate, especially in calm low-level winds. This gives a hint, that the development of the surface inversion is not exclusively governed by turbulent energy transports (discussed in Sect. 3.3 in detail).

\subsection{Transport scales}

Figure 7 shows wavenumber weighted power spectra of vertical velocity and temperature for cases SBL2 and SBL6. Wavenumber is herein defined as the inverse of the wavelength. Spectra from two flight levels are displayed for each case.

In case SBL2, the low-wind case, the temperature spectrum from the lowest flight level at $30 \mathrm{~m}$ (Fig. 7b) exhibits a structure dominated by two separate maxima. The maximum at smaller wavenumbers (at wavelengths of about $10 \mathrm{~km}$ ) is well known from other aircraft experiments (Drüe and Heinemann 2001; Heinemann 2002). It corresponds to a mixture of atmospheric waves and unintentional small aircraft height changes (pilots correcting height manually, resulting in vertical movements smaller than $10 \mathrm{~m}$ ). The maximum at higher wavenumbers corresponds to small-scale turbulence. It actually represents the lower-wavenumber end of the inertial subrange, but drops faster than $k^{-5 / 3}$ above roughly $k=3 \times 10^{-1} \mathrm{~m}^{-1}$ due to spectral attenuation of the entire turbulence measurement system. However, if the inertial subrange would extend far beyond the wavenumber corresponding to the sampling frequency, this drop would be compensated by aliasing (from A/D conversion; Vörsmann 1990). The division between both regimes is found near a wavenumber of roughly $k=1 \times 10^{-2} \mathrm{~m}^{-1}$.

For vertical wind, the structure is similar, but less distinct, due to overlying artefacts like spikes (e.g. at $k=1.67 \times 10^{-1}$ ) of instrument noise (e.g. caused by residual ripple of the instrument power supply or crosstalk from the electric systems of the aircraft). A spectral gap is visible only in the vertical velocity spectrum near $k=2 \times 10^{-3} \mathrm{~m}^{-1}$. 

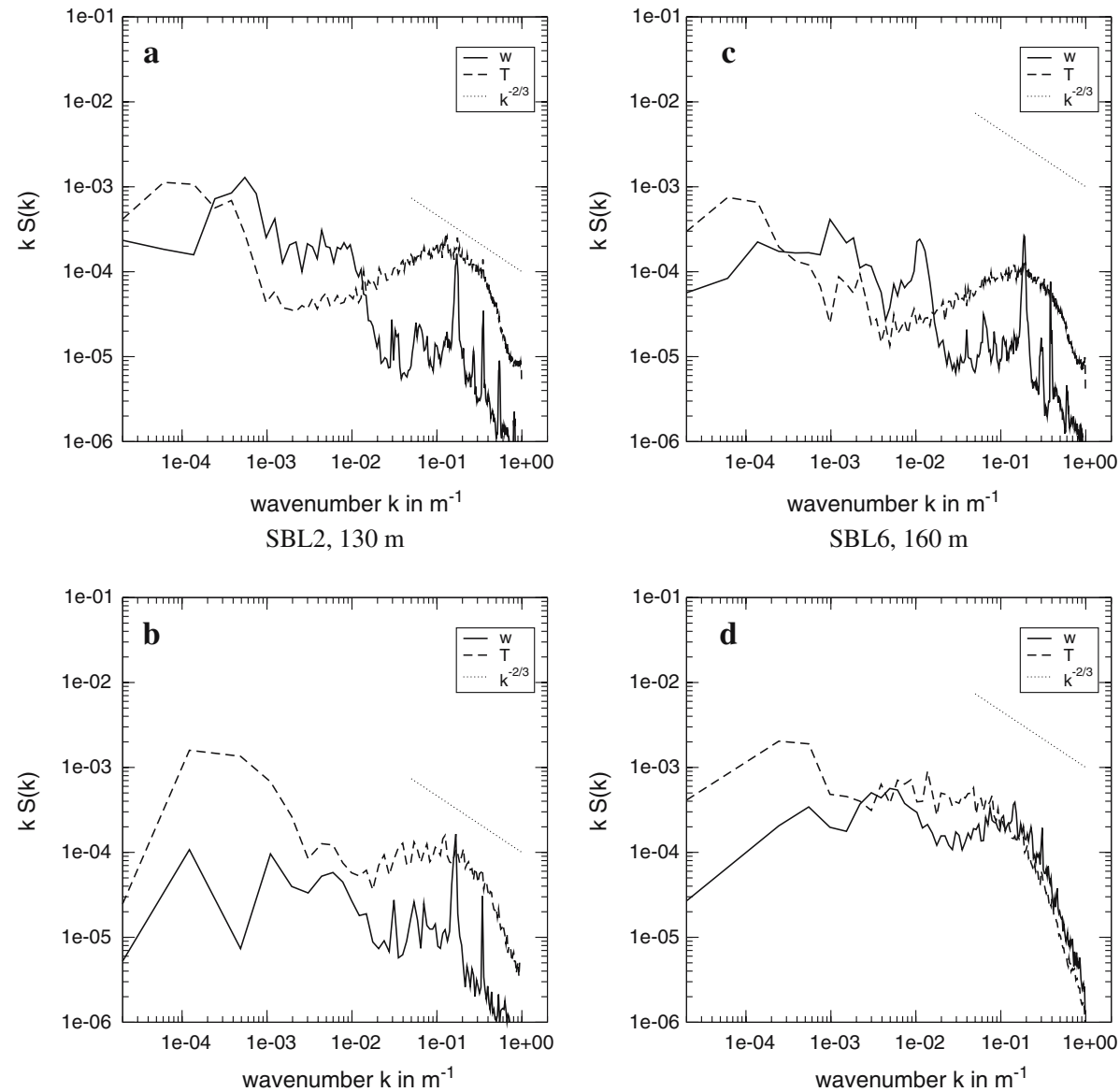

SBL2, $30 \mathrm{~m}$

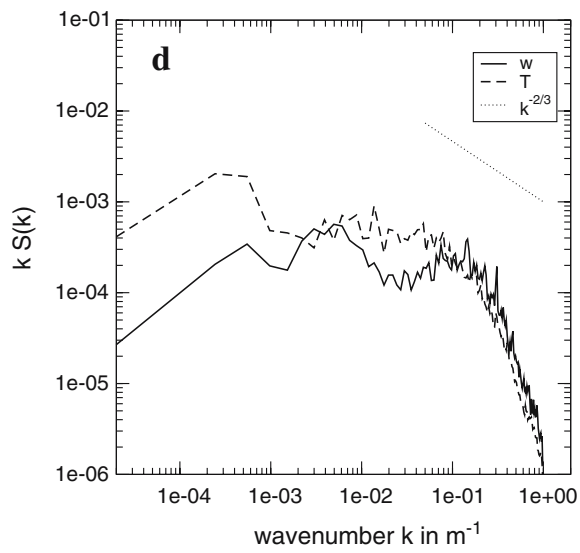

SBL6, $30 \mathrm{~m}$

Fig. 7 Power spectra $k S(k)$ of vertical velocity $(w)$, and Temperature $(T)$ versus wavenumber $k$. Left panels (a, b) show spectra from SBL2 (low wind), right panels (c, d) show spectra from SBL6 (high wind). Spectra shown in the upper panels $(\mathbf{a}, \mathbf{c})$ are calculated for the highest flight levels at $160 \mathrm{~m}$ an $130 \mathrm{~m}$, respectively. Lower panels $(\mathbf{b}, \mathbf{d})$ are calculated from the lowest flight levels at $30 \mathrm{~m}$. The dotted straight line gives the inertial subrange $k^{-2 / 3}$ slope

In the same case, but at the highest flight level at $130 \mathrm{~m}$ (Fig. 7a) the structure is basically the same, but the intensity at the wave motion scale is slightly reduced.

In case SBL6, due to higher near-surface winds, turbulence intensity on the small-scale is increased by a factor 10 (Fig. 7d), compared to SBL2. This indicates much stronger small scale turbulence, being apparently mechanically generated. The spectral gap between wavescale and small-scale motions in this case is shifted to about $k=2 \times 10^{-3} \mathrm{~m}^{-1}$. In case SBL6, spectra at the highest flight level at $160 \mathrm{~m}$ are almost identical to case SBL2.

In both cases, the frequency of the spectral gap at the lowest level matches well with the wavelengths corresponding to the Brunt-Väisälä frequency estimated from the measured vertical temperature gradients (SBL2: $\approx 90 \mathrm{~m} ;$ SBL6: $\approx 450 \mathrm{~m}$ ).

The multi-resolution decomposition by Vickers and Mahrt (2003) is an excellent method to separate turbulent and mesoscale contributions to the calculated fluxes of heat and momentum. 


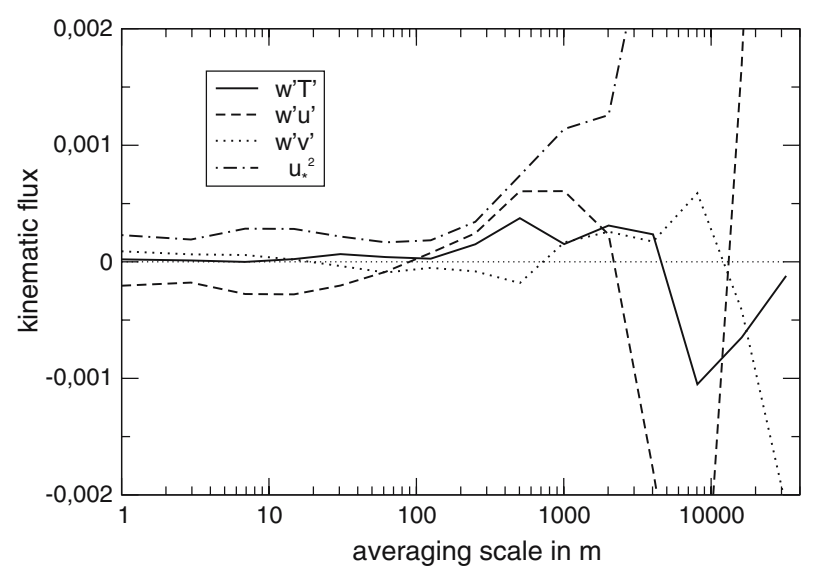

Fig. 8 Multi-resolution decomposition of cospectra (at $30 \mathrm{~m}$ ) for heat flux (solid), alongwind component of the momentum flux (dashed), crosswind component of the momentum flux (dotted) and magnitude of the momentum flux (dash-dot). SBL6, 0100 UTC

This analysis calculates the portion of turbulent fluxes that is affected by turbulent motions between $2 x$ and $x$, where $x$ denotes the averaging length. Figure 8 depicts the results of a multi-resolution decomposition of the lowest constant-level run during SBL6 (corresponding to Fig. 7d). The result is similar to the results presented by Vickers and Mahrt (2003), but with one exception: heat fluxes on the turbulent scale are almost zero in our case. For SBL2, results are similar, but numbers are even smaller. Hence, continuous turbulence is not a significant contributor to vertical fluxes. However, it will be demonstrated in the following sections that vertical transports are associated with intermittent bursts of turbulence.

\subsection{SBL heat budget}

\subsubsection{Turbulent fluxes}

Vertical turbulent heat transports are found to exhibit very small values. Even in turbulent outbreaks, they mostly do not exceed $10 \mathrm{~W} \mathrm{~m}^{-2}$ (Fig. 9). This applies to all cases, even at the lowest flight level. Significant turbulent fluxes were found to occur rather intermittently only, even in the high-wind case SBL6, where larger mean flux values were found compared to the low-wind case SBL2. Turbulence bursts typically extended over flight sections on the order of a few kilometres (Fig. 9). Above the lowest flight level (at $30 \mathrm{~m}$ ), all vertical fluxes of heat and momentum were below $0.5 \mathrm{~W} \mathrm{~m}^{-2}$ or $0.5 \times 10^{-3} \mathrm{Nm}^{-2}$ (which approximately corresponds to the level of random covariances from sensor noise).

Applying usual stationarity tests (e.g. Vickers and Mahrt 1997; Forrer and Rotach 1997) to the data shown in (Fig. 9) would classify them as nonstationary. Calculating averages over the whole length would hence be not permitted. However, more than $97 \%$ of the $500 \mathrm{~m}$ intervals pass the test for stationarity (of Vickers and Mahrt 1997). Cullen et al. (2007) have investigated ground-based turbulence measurements from Summit, and have come to the same conclusion that it is favorable to reduce averaging intervals to avoid issues of nonstationarity. Although only block averaging strictly satisfies Reynolds averaging, the error introduced by using linear detrending or high-pass filtering is fairly small if conditions are sufficiently stable (i.e. pass the stationarity test) over the averaging period (Moncrieff et al. 2004). 

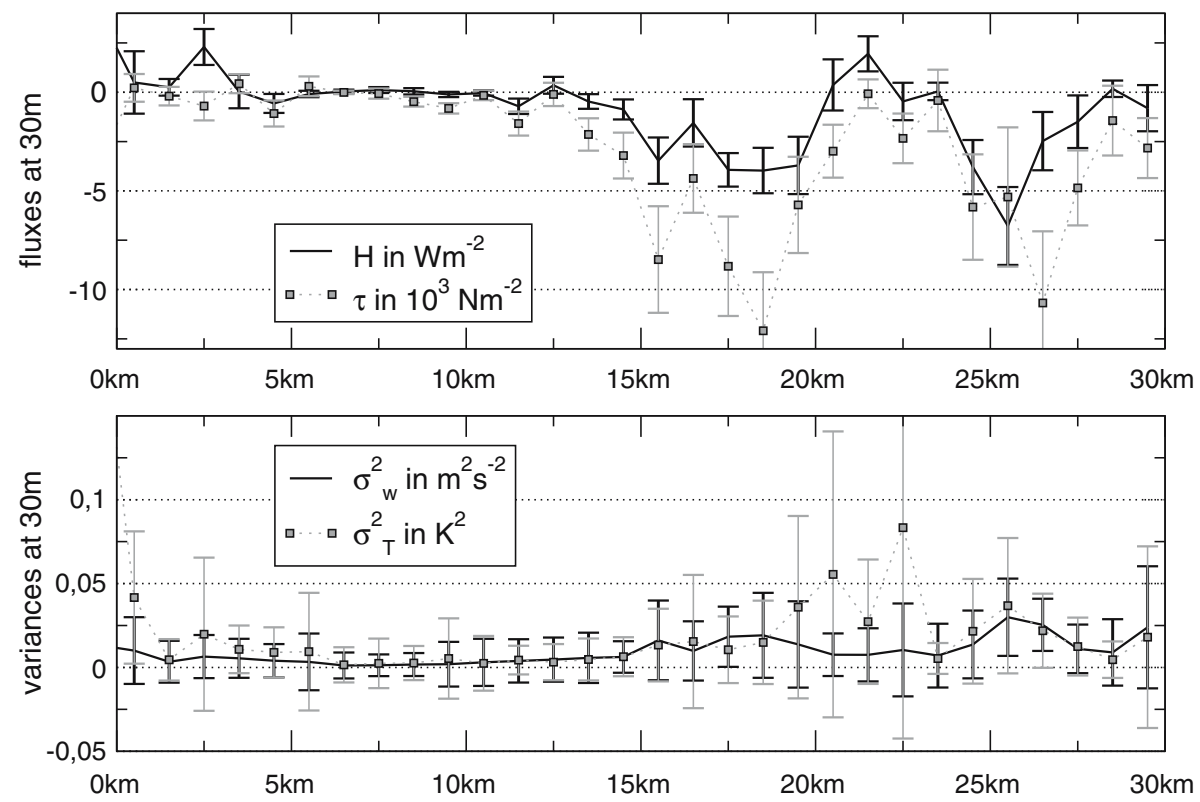

Fig. 9 Horizontal profiles of turbulent fluxes of heat and momentum (upper panel) and variances of vertical wind and temperature (lower panel) for a high-wind case (SBL6). $500 \mathrm{~m}$ averaging length (for clearness, only every second value is plotted), horizontal axis gives alongwind distance in $\mathrm{km}$. Errors are calculated from the covariance-function variance (Kaimal and Finnigan 1994)

It has to be considered that a significant fraction of the turbulent fluxes might not be measured because extremely small eddies (tens of $\mathrm{mm}$ in size) can contribute to the vertical heat transport in the SBL while the maximum wavenumber resolved by the Meteopod is limited to $k \approx 0.7 \mathrm{~m}^{-1}$. To estimate the turbulent heat transport in the non-resolved part of the spectrum, an assumed inertial subrange slope in the $w^{\prime} \theta^{\prime}$ cospectrum is used. The assumption is applied by taking the cospectrum values around $k=1 \times 10^{-2} \mathrm{~m}^{-1}$ and assuming a $k^{-7 / 3}$ slope for higher $k$. This estimation yields values of approximately half the random flux errors. Random and systematic errors were estimated from the variance of the flux values calculated along a horizontal run after Kaimal and Finnigan (1994), and Lenschow et al. (1994), see Drüe and Heinemann (2002).

Horst (1997) presented another method to assess the error of eddy covariance fluxes caused by the sensor response time. For our data, this method yields similarly small results as estimated above. Hence, no corrections for the spectral flux loss were applied (that would probably increase the random error).

Vertical wind and temperature variances also show an intermittent structure, but in areas where $\sigma_{T}$ reaches its highest values, $\sigma_{w}$ often remains very small (Fig. 9, at $22 \mathrm{~km}$ ). This indicates a poor correlation between $T$ and $w$, which is typical for the presence of gravity waves (Heinemann 2004). The largest flux values are linked to more moderate values of $\sigma_{T}$ that occur together with increased values of $\sigma_{w}$, e.g. at $25 \mathrm{~km}$ in Fig. 9.

Because of their extremely small values, turbulent vertical fluxes cannot fully explain the generation of the encountered surface inversion. In the low-wind case SBL2, divergence of the turbulent sensible heat flux between the ground and the lowest flight level corresponds to a cooling of less than $1 \mathrm{Kday}^{-1}$ (Fig. 10). For all higher levels, the divergence almost 

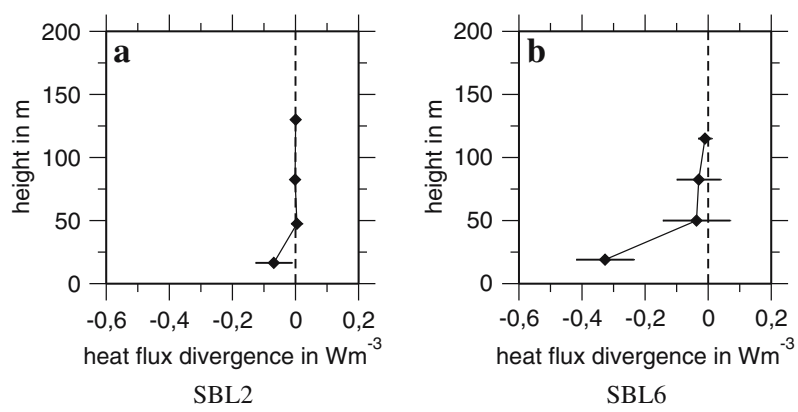

Fig. 10 Vertical profiles of turbulent heat flux divergence for a low-wind case (SBL2) and a high-wind case (SBL6). The lowest value was calculated using surface measurements at position S9 (Fig. 3). Note that negative values correspond to cooling

vanishes. Even in the high-wind case SBL6, sensible heat flux divergence does not exceed values corresponding to a cooling of $0.1 \mathrm{Kday}^{-1}$ except for the lowest layer. Apparently, secondary terms of the SBL heat budget that are usually neglected, become significant in the IGLOS cases, in particular in low-wind situations. Among these terms, longwave radiation divergence was found to be a major contributor and is discussed in the next section.

Horizontal advection was estimated from aircraft data using horizontal temperature gradients and winds measured on the flight sections around the outer box of the flight pattern (Fig. 3). Similarly, vertical advection was estimated from the divergence of the horizontal winds measured along the outer box and vertical temperature gradients measured in the centre of the box. Regarding the measurement uncertainties, the results were not significantly different from zero. Hence, neither horizontal nor vertical advection could be proven to give a major contribution to the SBL energy budget.

\subsubsection{Radiative cooling}

Radiative cooling is usually assumed to occur at the ground. The cooling is then transferred to the atmosphere by downward turbulent heat fluxes. Only in the presence of very strong vertical temperature gradients, a considerable clear-air radiative cooling can occur aloft from the ground (Mahrt 1999).

Such gradients were observed in the SBL at Summit. Hence, heating/cooling rates for the IGLOS cases are calculated from measurements of the radiation sensors on board the aircraft. This procedure yields vertical profiles of radiation fluxes and net radiation. These profiles extend from $900 \mathrm{~m}$ height down to about $35 \mathrm{~m}$ above ground. The error of the longwave net radiation divergence was estimated from the variability of longwave radiation fluxes on short horizontal flight sections to be around to $0.05 \mathrm{~W} \mathrm{~m}^{-3}$.

Among these profiles, longwave net radiation was identified as the dominant term to radiative cooling. In the low and moderate wind cases, vertical profiles of longwave net radiation suggest a significant cooling below $400 \mathrm{~m}$. The highest values of radiative cooling are found at the lowest level (at $35 \mathrm{~m}$ ), but values of about $-0.1 \mathrm{~W} \mathrm{~m}^{-3}$ are also present at the upper levels (see Fig. 11). These values always occur below the thermal SBL height $h_{T}(200 \mathrm{~m}$ in case SBL2) but did not show any correlation with the low-level wind maximum height $h_{v}$, as expected.

A detailed study of the radiation forcing for the SBL has been undertaken by ETH Zürich, based on radiation measurements at the $50 \mathrm{~m}$ mast (Hoch 2005). These results suggest that 

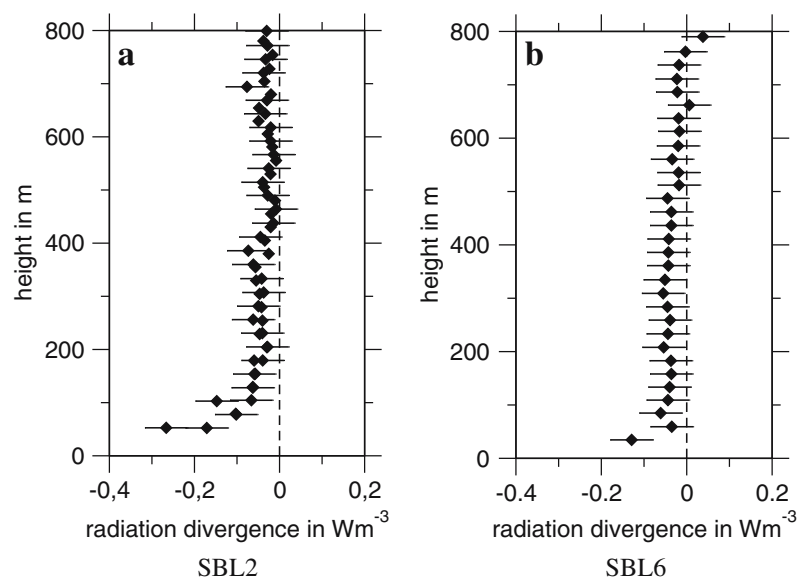

Fig. 11 Vertical profiles of longwave net radiation divergence for a low-wind case (SBL2) and a high-wind case (SBL6). Invisible error bars are smaller than the symbol size. Negative values correspond to cooling. Note that the scaling is different from Fig. 10

during nighttime in summer, the divergence of the upward longwave radiation flux dominates the radiation budget. Between $10 \mathrm{~m}$ and $50 \mathrm{~m}$ above the ground, a radiative cooling rate of about $10 \mathrm{Kday}^{-1}$ is found, which corresponds to $0.15 \mathrm{Wm}^{-3}$. This value agrees well with our measurements.

During the IGLOS period in Arctic summer, the PBL did exhibit a clear daily cycle in near surface temperatures. PBL stratification was usually neutral at daytime. Around 1900 UTC (1700 local) the stratification turned stable and a SBL developed. Assuming that the SBL is mostly generated by the observed radiative cooling rate of $10 \mathrm{Kday}^{-1}$, an inversion strength of $4.5 \mathrm{~K}$ would be expected around $0500 \mathrm{UTC}$ (0300 local). In fact, the observed inversion strength was about $5 \mathrm{~K}$ (between $50 \mathrm{~m}$ and $200 \mathrm{~m}$ above ground) during SBL2 (Fig. 4). It hence appears that the thermal SBL height $h_{T}$ is determined by a radiation equilibrium rather than by turbulence, at least in low to moderate wind conditions.

During SBL6, radiative cooling was slightly weaker than during SBL2 (Fig. 11) while cooling by sensible heat-flux divergence was four times stronger compared to SBL2 (Fig. 10). Except for the lowest layer, where the turbulent heat-flux divergence dominates, both divergences are nearly equal contributors to the SBL heat budget.

This helps to explain why $h_{C Q E}$-that is mainly based on turbulence measures-matches much better with the observed turbulent SBL height $h_{v}$ than with the thermal SBL height $h_{T}$ in low wind cases, whereas, $h_{v}$ approaches $h_{T}$ and hence $h_{C Q E}$ in high wind cases.

It can be concluded that the radiation divergence is an important factor in the SBL energy budget. Especially in low-wind situations, turbulent flux divergence plays only a minor role.

\section{Intermittent turbulence}

\subsection{Turbulent event fraction}

In order to investigate intermittent atmospheric turbulence, a measure is needed to quantify the strength of the intermittency. In the past, different approaches have been made to create such a measure (e.g. Kondo et al. 1978; Howell and Sun 1999). We follow Doran (2004), 


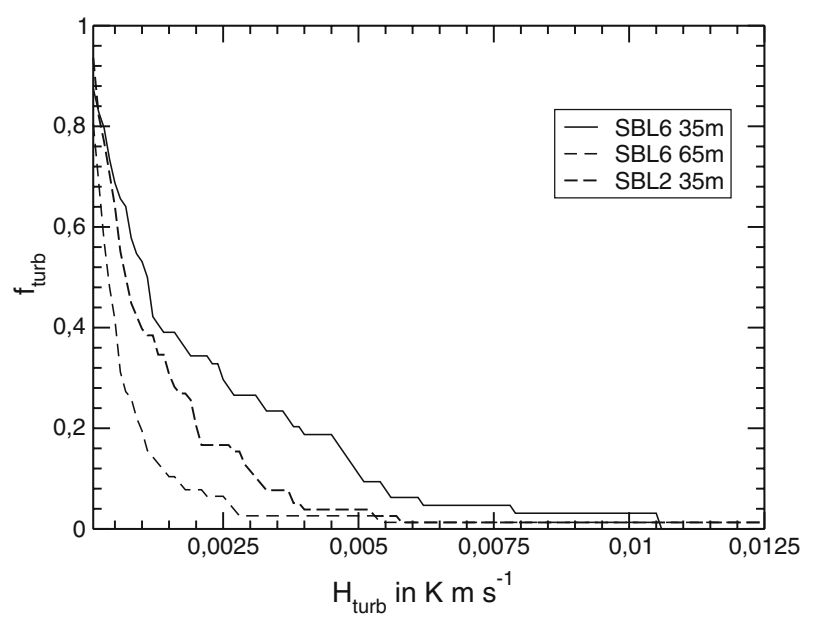

Fig. 12 Dependency of turbulent event fraction $f_{\text {turb }}$ on the choice of threshold $H_{t u r b}$ for three exemplary constant-level runs from SBL2 and SBL6

who introduced a turbulent event fraction $f_{\text {turb }}$ for this purpose. $f_{\text {turb }}$ is defined as the time occupied by turbulent events divided by the total time. A turbulent event is defined by Doran (2004) as a 60-s interval, where the kinematic heat flux $\overline{w^{\prime} T^{\prime}}$ exceeds (i.e. is more negative) than $-0.015 \mathrm{~K} \mathrm{~m} \mathrm{~s}^{-1}$. Larger values of $f_{\text {turb }}$ correspond to stronger turbulence (less intermittency), which we find more intuitive than e.g. the measure introduced by Kondo et al. (1978)

Since we used aircraft measurements, according to Taylor's hypothesis, we must use spatial intervals instead of temporal intervals. The terrain in the measurement showed neither from visual inspection nor from airborne measurements (surface albedo and geometric roughness) any surface inhomogeneities from which a terrain influence could be expected. Hence we define a turbulent event as a 500-m interval, where the kinematic heat flux $\overline{w^{\prime} T^{\prime}}$ exceeds a threshold $H_{\text {turb }} f_{\text {turb }}$ is then calculated for each flight section as the number of 500-m intervals where $\left|\overline{w^{\prime} T^{\prime}}\right|>H_{\text {turb }}$ divided by the total number of 500-m intervals in this flight section.

The threshold values $H_{\text {turb }}$ used by Doran (2004) or Coulter and Doran (2002) could not be used for IGLOS because they were chosen for situations with much larger downward fluxes. Hence, the dependency of $f_{\text {turb }}$ on the choice of $H_{\text {turb }}$ was considered: assuming two basic states-turbulent and nonturbulent-a plot of $f_{\text {turb }}$ versus threshold should exhibit a clear bend that separates a sharp decrease of $f_{\text {turb }}$ (with increasing threshold) for smaller thresholds (i.e. many intervals exhibit low fluxes) and a much weaker decrease of $f_{\text {turb }}$ for larger thresholds (i.e. event fluxes are mostly much larger). $H_{\text {turb }}$ should be chosen close to this bend. By visual inspection (see Fig. 12 for example), $H_{\text {turb }}=0.0025 \mathrm{~K} \mathrm{~m} \mathrm{~s}^{-1}$ was identified to satisfy this condition for most flight sections.

\subsection{Dependence of $f_{\text {turb }}$ on gradient Richardson number}

In order to investigate the dependence of the turbulent event fraction on gradient Richardson number, $f_{\text {turb }}$ was calculated for all constant level runs performed during IGLOS. The typical length of these runs is $30 \mathrm{~km}$ (Fig. 3). Data from flight sections where no turbulent events are 


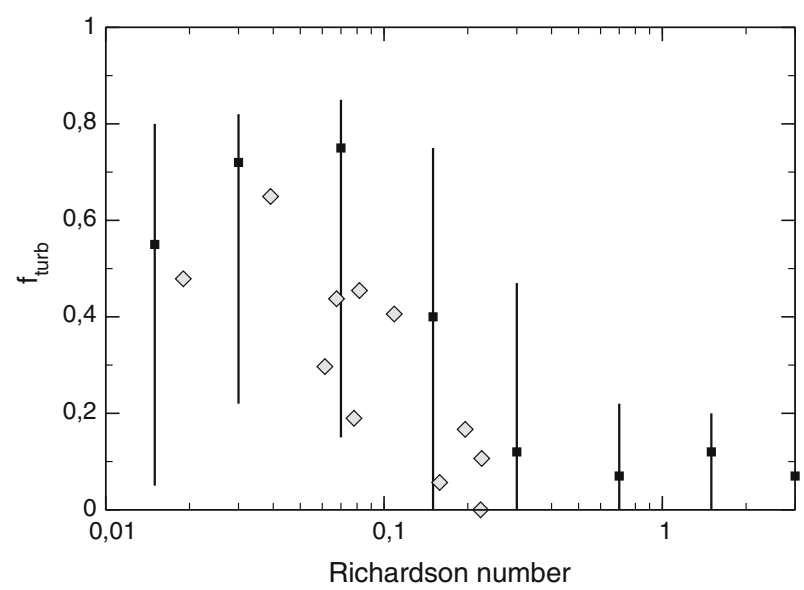

Fig. 13 Turbulent event fraction versus gradient Richardson number. Diamonds represent all constant level runs from all IGLOS cases: open symbols correspond to the respective lowest flight level, squares and the vertical error bars represent values by Doran (2004)

detected were excluded because in this case it cannot be decided whether the flow is laminar or continuous turbulence is present but too weak to be measured. In Fig. 13, the turbulent event fraction $f_{\text {turb }}$ is plotted against gradient Richardson number

$$
\operatorname{Ri}=\frac{\frac{g}{\theta} \frac{\partial \theta}{\partial z}}{\left(\frac{\partial u}{\partial z}\right)^{2}+\left(\frac{\partial v}{\partial z}\right)^{2}}
$$

Here $g$ is the acceleration of gravity and $u$ and $v$ horizontal wind components. Vertical gradients were calculated by linear regression from small variations of the aircraft height during horizontal flight sections. Bange and Roth (1999) and Drüe and Heinemann (2001) demonstrated that this procedure is superior to estimating vertical gradients from single vertical soundings because it yields values valid at the actual height of a constant level run. Ri was then calculated for each constant level run.

On flight sections where intermittent turbulence was encountered, (Fig. 13) values clearly show a dependence on Ri. The maximum $f_{\text {turb }}$ value 0.7 is found at $\mathrm{Ri}=0.04$ and a continuous decrease until 0.1 at $\mathrm{Ri}=0.3$. Figure 13 also shows the results presented by Doran (2004). He grouped 700 data points into bins along the $R i$-axis. Symbols and bars denote median and 10th to 90th percentile values of all values in the respective bin (not to be confused with mean and rms error). Theses values are derived from measurements at roughly 4-20 m height at Hanford site, Washington, USA.

Although the experiment environment and methods of calculation are completely different, they fit very well with the IGLOS values. IGLOS values are generally lower than the median values by Doran (2004), but they are all well above the respective 10th percentile values. Similar coincidence (not shown) can be found to the behaviour described by Kondo et al. (1978). Hence, our results support the supposition by Doran (2004) that this dependence of turbulent event fraction $f_{\text {turb }}$ on gradient Richardson number is a universal property of the SBL. 


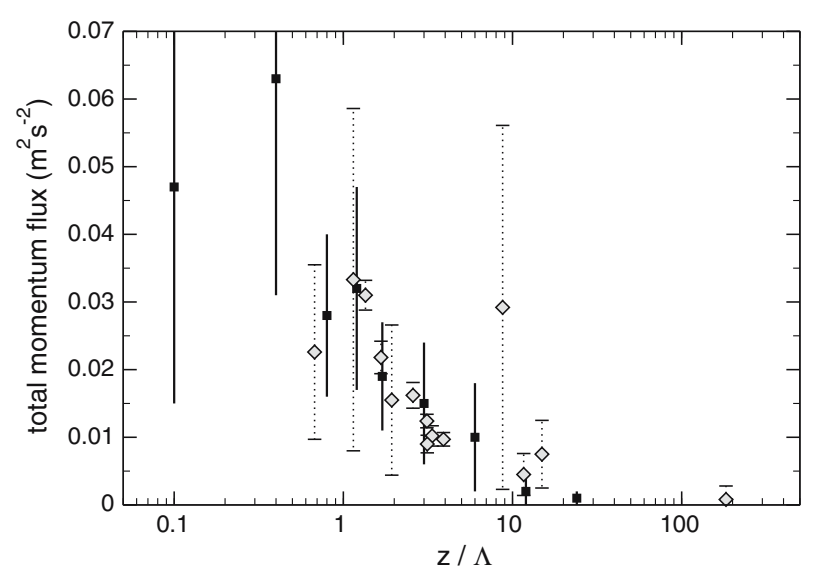

Fig. 14 Magnitude of the momentum flux versus stability. Diamonds represent all IGLOS constant level runs, vertical bars mark the results (mean and standard deviation) by Heinemann (2004)

\subsection{Turbulent event fluxes}

For every constant level run from IGLOS, a local stability parameter $z / \Lambda$ was calculated using

$$
\Lambda=-\frac{u_{L}^{3}}{\kappa \frac{g}{\theta} \overline{w^{\prime} \theta^{\prime}}}
$$

where $\overline{w^{\prime} \theta^{\prime}}$ denotes kinematic heat flux, $\kappa$ is von Kármán's constant and $u_{L}$ the local friction velocity

$$
u_{L}=\left(\overline{u^{\prime} w^{\prime}}+\overline{w^{\prime} v^{\prime}}\right)^{\frac{1}{4}}
$$

An analysis of the dependence of the turbulent fluxes on local stability was performed by taking complete flight legs and by selecting turbulent events. For complete flight legs, flux values showed a huge scatter and no systematic dependence was found. In contrast, the calculation of turbulent fluxes and $z / \Lambda$ just for the turbulent parts of each leg (i.e. omitting the $500 \mathrm{~m}$ intervals where $\left|\overline{w^{\prime} \theta^{\prime}}\right|<H_{\text {turb }}$ ) yielded a more consistent picture.

The momentum flux $\tau_{L}=\rho u_{L}^{2}$ shows a dependence on stability (Fig. 14) that is very similar to the behaviour found in previous studies on continuous SBL turbulence (e.g. Heinemann 2004; Mahrt 1998). The values of the momentum flux between $z / \Lambda=0.3$ and 20 (Fig. 15) are almost identical to the values reported by Heinemann (2004). The apparent dependence of $\tau_{L}$ on $z / \Lambda$ emerges from the fact that both are functions of $u_{L}$ rather than from a universal relationship. Figure 14 however illustrates well that the momentum flux in continuous turbulence and in the turbulent parts of intermittent turbulence exhibit very similar values over a wide range of stability.

The plot of the kinematic heat flux versus stability (Fig. 15) shows a larger scatter compared to the momentum flux. Unfortunately it is not possible to verify the decrease of $\overline{w^{\prime} \theta^{\prime}}$ for very small $z / \Lambda$ values due to the more stable stratification in the IGLOS cases. Kinematic 


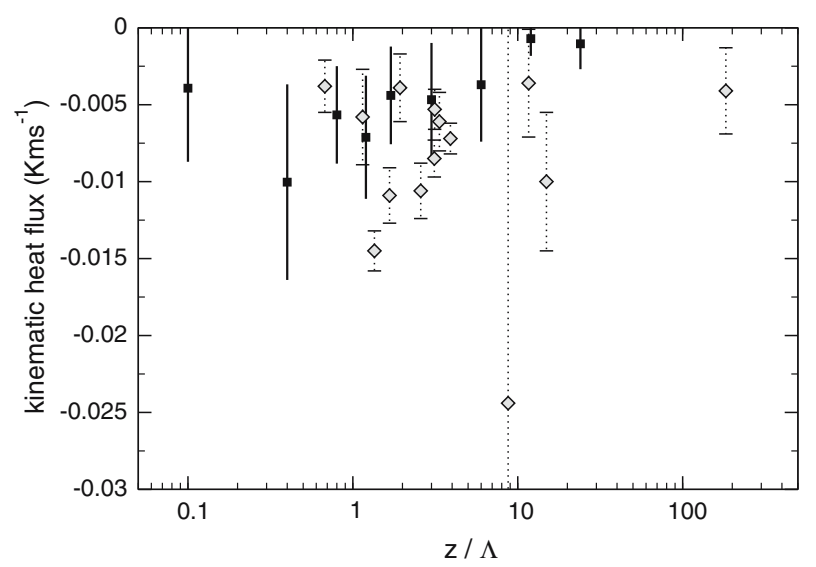

Fig. 15 Kinematic heat flux versus stability. Symbols as in Fig. 14

heat flux values of Heinemann (2004) and of the present study do not agree as well as the momentum flux values.

Usually, in the region $z / \Lambda>1$ turbulence is assumed to be continuous and local scaling is assumed to be valid (Holtslag and Nieuwstadt 1986). Intermittent turbulence would be expected only for $z / \Lambda>10$. But as Holtslag and Nieuwstadt pointed out, their often-cited borderline between $z$-less scaling and intermittent turbulence regions was chosen "somewhat arbitrarily" to outline a region where local scaling is applicable to their data. They admit that it represents "a drastic simplification ... near the top of the SBL". As seen in Fig. 13, turbulence was never continuous for any of these horizontal runs. Apparently, turbulence turns intermittent even when $z / \Lambda<10$ in our cases.

\section{Summary and conclusions}

In the present study, characteristics of intermittent turbulence in the upper SBL above an almost ideal horizontally homogeneous area are investigated. The experiment IGLOS was conducted around Summit Camp in central Greenland during Arctic summer (29 June-25 July, 2002). It represents one of the rare aircraft based studies in the SBL. Flight data were combined with measurements of turbulence and radiative fluxes from a $50 \mathrm{~m}$ mast at Summit Camp, Greenland. An in-depth analysis of the tower data, however, will be subject to a forthcoming separate publication by the ETH group.

Six flight missions were performed on clear nights under high pressure conditions. In all cases, well-developed SBLs were found. Although near-surface wind speeds reached up to almost $15 \mathrm{~m} \mathrm{~s}^{-1}$, the surface inversion thickness never exceeded roughly $100 \mathrm{~m}$. Turbulent SBL height $h_{v}$ was found to be much smaller than the thermal SBL height $h_{T}$, especially under low-wind conditions. SBL height parameterizations that are based on turbulence measures were found to agree better with the turbulent SBL height $h_{v}$.

A comparison of vertical profiles of turbulent heat flux divergence and longwave radiation flux divergence reveals that radiative cooling is always a significant contributor to the SBL energy budget. In low-wind situations, radiation flux divergence exceeds values observed in previous studies (e.g. Mahrt 1985) and becomes the dominating contributor to the energy 
budget. This behaviour supports model calculations by Garratt and Brost (1981), who had also predicted $h_{v}<h_{T}$ in this case.

Turbulent fluxes were found to occur only intermittently. Even in low-level winds of more than $8 \mathrm{~ms}^{-1}$ and at the lowest flight level $(\approx 30 \mathrm{~m})$ turbulence in the upper SBL remained intermittent. The horizontal scale of such turbulence bursts was of the order of few kilometres. Turbulent event fraction $f_{\text {turb }}$ in the SBL shows the same dependence on the Richardson number as reported by previous studies of near-surface measurements (Doran 2004). An investigation of the turbulent fluxes inside bursts of turbulence revealed a stability dependence that is very similar to results reported by other authors (Heinemann 2004; Mahrt et al. 1998) from measurements in fully continuous turbulence.

Since identical vertical transports occur in a shorter period of time if turbulence is intermittent, it would be expected that fluxes inside turbulent bursts tend to be larger in magnitude compared to continuous turbulence. This would explain why turbulent heat flux values in just the turbulent parts (of our study) tend to be larger in magnitude compared to continuous turbulence (Heinemann 2004).

From IGLOS, there are also some implications for further (aircraft based) studies in the SBL. For example, using a slower flying plane could help to increase spatial resolution and, in turn, flux measurement accuracy. This would reduce the required length of horizontal runs and would allow more detailed flux profiles. Setting up an array of microbarographs could help to clear up the role of atmospheric waves (Böhme et al. 2004). Calculating fluxes only during turbulent bursts might be a method to overcome the lack of (usable) experimental data from extremely stable stratified SBLs. Finally, measurements of longwave radiation flux profiles are found to be essential for any complete investigation of the SBL heat budget.

Acknowledgements IGLOS was supported by Deutsche Forschungsgemeinschaft (DFG) under grant He 2740/2. Use of Polar 2 was granted by Alfred-Wegener-Institut (AWI), Bremerhaven. Polar 2 was operated by Deutsches Zentrum für Luft- und Raumfahrt (DLR), Oberpfaffenhofen. METEOPOD was operated by Optimare, Bremerhaven.

Tower and surface radiation measurements from Summit Camp were supplied from Eidgenössische Technische Hochschule (ETH), Zürich. The authors like to thank S. Hoch, P. Schelander and A. Ohmura from ETH Zürich for a fruitful cooperation during IGLOS and S. Gregory from University of Colorado for helpful comments on the manuscript.

\section{References}

Bange J, Roth R (1999) Helicopter-borne measurements in the nocturnal boundary layer over land - a case study. Boundary-Layer Meteorol 92: 295-325

Böhme T, Hauf T, Lehmann V (2004) Investigation of short-period gravity waves with the Lindenberg 482 MHz tropospheric wind profiler. Quart J Roy Meteorol Soc 130(603): 2933-2952

Cassano JJ, Parish TR, King JC (2001) Evaluation of turbulent surface flux relationships for the stable surface layer over halley, Antarctica. Mon Wea Rev 129: 26-46

Colbeck SC (1997) Model of wind pumping for layered snow. J Glaciol 43: 60-65

Coulter RL, Doran JC (2002) Spatial and temporal occurrences of intermittent turbulence during CASES-99. Boundary-Layer Meteorol 105: 329-349

Cullen NJ, Steffen K, Blanken PD (2007) Nonstationarity of turbulent heat fluxes at Summit, Greenland. Boundary-Layer Meteorol 122: 439-455

Doran JC (2004) Characteristics of intermittent turbulent temperature fluxes in stable conditions. BoundaryLayer Meteorol 112: 241-255

Drüe C, Heinemann G (2001) Airborne investigation of Arctic boundary layer fronts over the marginal ice zone of the Davis Strait. Boundary-Layer Meteorol 101: 261-292

Drüe C, Heinemann G (2002) Turbulence structures over the marginal ice zone under flow parallel to the ice edge: measurements and parameterizations. Boundary-Layer Meteorol 102: 83-116 
Drüe C, Heinemann G (2003) Investigation of the greenland atmospheric boundary layer over summit 2002 (IGLOS). Field phase report., Vol. 447 of Reports on Polar and Marine Research., 81 pp

Finnigan JJ, Clement R, Malhi Y, Leuning R, Cleugh H (2003) A re-evaluation of long-term flux measurement techniques part I: averaging and coordinate rotation. Boundary-Layer Meteorol 107(1): 1-48

Foken T, Wichura B (1996) Tools for quality assessment of surface-based flux measurements. Agric For Meteorol 78: 83-105

Forrer J, Rotach MW (1997) On the structure in the stable boundary layer over the Greenland ice sheet. Boundary-Layer Meteorol 85: 111-136

Garratt J, Brost R (1981) Radiative cooling effects within and above the nocturnal boundary layer. J Atmos Sci 38(12): 2730-2746

Handorf D (1996) Zur Parameterisierung der stabilen atmosphärischen Grenzschicht über einem antarktischen Schelfeis, Vol. 204 of Reports on Polar Research 133 pp

Handorf D, Foken T, Kottmeier C (1999) The stable atmosphere boundary layer over an antarctic ice sheet. Boundary-Layer Meteorol 91: 165-189

Heinemann G (1998) Katabatic wind and Boundary Layer Front Experiment around Greenland ("KABEG 97”), Vol. 269 of Reports on Polar Research. 94 pp

Heinemann G (1999) The KABEG'97 field experiment: an aircraft-based study of katabatic wind dynamics over the Greenland ice sheet. Boundary-Layer Meteorol 93: 75-116

Heinemann G (2002) Aircraft-based measurements of turbulence structures in the katabatic flow over Greenland. Boundary-Layer Meteorol 103: 49-81

Heinemann G (2004) Local similarity properties of the continously turbulent stable boundary layer over greenland. Boundary-Layer Meteorol 112: 283-305

Hoch SW (2005) Radiative flux divergence in the surface boundary layer. A study based on observations at Summit, Greenland. Ph.D. thesis, ETH Zürich, Switzerland, 180 pp

Holtslag AAM, Nieuwstadt FTM (1986) Scaling the atmospheric boundary layer. Boundary-Layer Meteorol 36: 201-209

Horst TW (1997) A simple formula for attenuation of eddy fluxes measured with first-order-response scalar sensors. Boundary-Layer Meteorol 82: 219-233

Howell JF, Sun J (1999) Surface-layer fluxes in stable conditions. Boundary-Layer Meteorol 90: 495-520

Kaimal JC, Finnigan JJ (1994) Atmospheric boundary layer flows. Oxford University Press, New York, 289 $\mathrm{pp}$

King J (1990) Some measurements of turbulence over an antarctic ice shelf. Quart J Roy Meteorol Soc 116: 379-400

Kondo J, Kanechika O, Yasuda N (1978) Heat and momentum transfers under strong stability in the atmospheric surface layer. J Atmos Sci 35: 1012-1021

Lenschow DH, Mann J, Kristensen L (1994) How long is long enough when measuring fluxes an other turbulence statistics?. J Atmos Oceanic Technol 11: 661-673

Mahrt L (1981) Modeling the depth of the stable boundary-layer. Boundary-Layer Meteorol 21: 3-19

Mahrt L (1985) Vertical structure and turbulence in the very stable boundary layer. J Atmos Sci 42(22): 2333-2349

Mahrt L (1998) Stratified atmospheric boundary layers and breakdown of model. Theor Comput Fluid Dynam 11: 263-279

Mahrt L (1999) Stratified atmospheric boundary layers. Boundary-Layer Meteorol 90: 375-396

Mahrt L, Sun J, Blumen W, Delany T, Onkley S (1998) Nocturnal boundary layer regimes. Boundary-Layer Meteorol 88: 255-278

Moncrieff J, Clemens R, Finnigan J, Meyers T (2004) Averaging, detrending, and filtering of eddy covariance time series. In: Lee X, Massman W, Law B (eds) Handbook of micrometeorology: a guide for surface flux measurement and analysis, Vol. 29 of Atmospheric and oceanographic sciences library. Springer Berlin Chapt. 2, pp. 7-32, ISBN: 978-1-4020-2264-7

Nieuwstadt FTM (1984) Some aspects of the turbulent stable boundary layer. Boundary-Layer Meteorol 30: $1-55$

Oerlemans J, Vugts H (1993) A meteorological experiment in the ablation zone of the Greenland ice sheet. Bull Amer Meteorol Soc 74: 355-365

Ohmura A, Gilgen H, Hegner H, Müller G, Wild M, Dutton E, Forgan B, Fröhlich C, Philipona R, Heimo A, König-Langlo G, McArthur B, Pinker R, Whitlock CH, Dehne K (1998) Baseline surface radiation network (BSRN/WCRP): new precision radiometry for climate research. Bull Amer Meteorol Soc 79: 2115-2136

Schelander P, Hoch SW, Bourgeois CS, Ohmura A, Calanca P (2004) Climatic conditions during the ETH measurement campaign at summit, Greenland, 2001-2002. In: EGU 1st general assembly, 25-30 april 2004, Nice, France, Vol.6 of geophysical research Abstracts 
Stull RB (1988) An introduction to boundary layer meteorology. Kluwer Academic Publishers, Dordrecht $666 \mathrm{pp}$

Van de Wiel BJH, Ronda RJ, Moene AF, De Bruin HAR, Holtslag AAM (2002) Intermittent turbulence and oscillations in the stable boundary layer over land. Part I: a bulk model. J Atmos Sci 59: 942-958

Vickers D, Mahrt L (1997) Quality control and flux sampling problems for tower and aircraft data. J Atmos Oceanic Technol 14: 512-526

Vickers D, Mahrt L (2003) The cospectral gap and turbulent flux calculations. J Atmos Oceanic Technol 20: 660-672

Vörsmann P (1990) Meteopod, an airborne system for measurements of mean wind, turbulence, and other meteorological parameters. Onde Electrique 70: 31-38

Xiao J, Bintanja R, Déry S, Mann GW, Taylor PA (2000) An intercomparison among four models of blowing snow. Boundary-Layer Meteorol 97: 109-135

Zilintinkevich S, Baklanov A (2002) Calculation of the height of the stable boundary layer in practical applications. Boundary-Layer Meteorol 105: 389-409 